\title{
Effect of Pure and Binary Fluids on Thermal Performance of Closed Loop Pulsating Heat Pipe
}

\author{
J. Venkata Suresh, P. Bhramara, K. Nagasri
}

\begin{abstract}
Pulsating heat pipe is the raising methodology of cooling systems in many areas. CLPHP is a passive mode of phase change heat transfer device having potential to transfer heat from source to sink in less span. Heat transfer performance of this method is improving day by day as giving less thermal resistance. Number of experimentations are conducting to increase the efficiency of pulsating heat pipes in many aspects i.e. varying lengths, working fluids, number of turns, different fill ratios, heat inputs and orientation. As taking part of these research a five turn closed loop pulsating heat pipe (of tube inner diameter $2 \mathrm{~mm}$, outer diameter 3mm; adiabatic section length $170 \mathrm{~mm}$, condensation section length is $50 \mathrm{~mm}$, evaporation section length is 42mm) working with pure and binary fluids (water-acetone, water-ethanol) compared with water, Acetone, Ethanol with heat inputs 20w, 40w, 60w, 80w, and fill ratio 50\%, also the orientations are horizontal and vertical. The analysis from the results obtained was the thermal resistance of all working fluids is drastically diminishing from $20 \mathrm{w}$ to $40 \mathrm{w}$ heat input and slowly from $40 w$ to $80 w$.
\end{abstract}

Keywords: Closed Loop Pulsating Heat Pipe, Binary fluids, Thermal resistance, Thermal Performance.

\section{INTRODUCTION}

$\mathrm{H}_{\mathrm{e}}$ eat pipes are Heat transfer devices. They are Hollow cylindrical pipes filled with a small amount of fluid that evaporates to produce heat. This heat is then rejected from another end for its application on industrial processes. For example, it is used in Air Conditioning and Refrigeration application. Basic heat pipe model was given in the fig1.1.

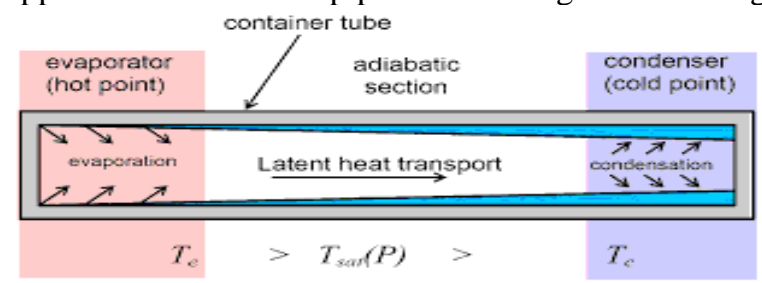

Fig.1.1.Heat pipe structure

Revised Manuscript Received on February 05, 2020.

* Correspondence Author

J. Venkata Suresh*, Asst. prof. \& Research Scholar, JNTUCEH, Department of Mechanical Engineering, GRIET, Hyderabad, Telangana, India. E-mail:venkatasureshj@gmail.com

Dr. P. Bhramara, professor, Department of Mechanical Engineering, JNTU College of Engineering, Hyderabad, Telangana, India.

E-mail: bhramara74@jntuh.ac.in

K. Nagasri,, M.Tech (Thermal Engineering) Student, Department of Mechanical Engineering, GRIET, Hyderabad, Telangana, India. E-mail: nagasri.888@gmail.com.

(C) The Authors. Published by Blue Eyes Intelligence Engineering and Sciences Publication (BEIESP). This is an open access article under the CC BY-NC-ND license (http://creativecommons.org/licenses/by-nc-nd/4.0/)

\subsection{Heat pipe working principle:}

Heat pipe is generally self-heat recovery devices that is used to transfer heat from one end to another with minimum temperature differences and also to pass the heat across internal surface. Many terms have to be taken into consideration while choosing a pipe for application on industrial devices. They are manufactured in different shapes such as round or flat shapes.

\subsection{Function And Design of Heat Pipe:}

They is enclosed under vacuum with a sufficient, preset amount of working fluid. At initial state, the working water is contained inside the wick lined structure that lines the inside area of the heat pipe. When a heat injection, an electronic component, generates heat for input, the fluid/water inside the heat pipe evaporates in vapor which is known as the evaporator section or bottom end. The water vapor immediately spreads and goes to the other end (condenser) of the heat pipe, hence using the pressure generated by the minimum temperature difference. At the opposite end known as the condenser part, the working fluid/water rejects out its latent heat, which is rejected or produced to an external device i.e. heat sink. The water then again returns to liquid/fluid form, and the wick structure inside the heat pipe relatively or passively pumps the fluid/water in reverse direction to the evaporator section by using capillary force. By using this liquid and vapor phases, heat transport mechanism becomes extremely fluent and efficient. Because of heat pipes closed loop design, heat pipes works continuously and passively, gaining a very reliable and passive part in your thermal management system.

\subsection{PULSATING HEAT PIPE}

A PHP consists of a plain meandering tube of capillary dimensions with many U-turns . In contrast to a conventional heat pipe, there is no additional capillary structure inside the tube. There are two ways to arrange the tube: open loop and closed loop. As the names suggest, in a closed loop structure, the tube is joined end-to-end. The tube is first evacuated and then filled partially with a working fluid, which distributes itself naturally in the form of liquid-vapor plugs and slugs inside the capillary tube. One end of this tube bundle receives heat, transferring it to the other end by a pulsating action of the liquid-vapor/bubble-slug system. There may exist an optional adiabatic zone in between. Also, one or more flow-direction control check valves may be introduced at suitable locations to augment the performance. Design of pulsating heat pipe is as shown in the fig1.2.

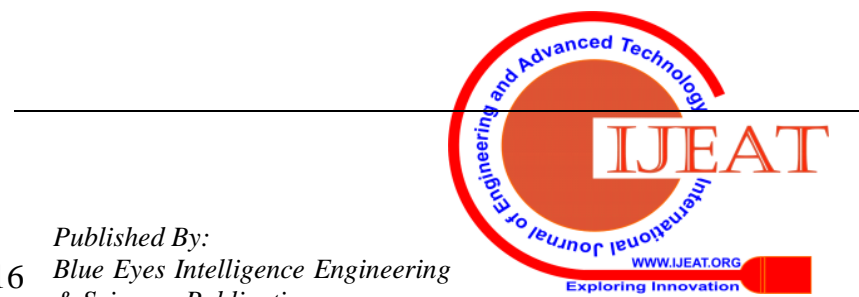




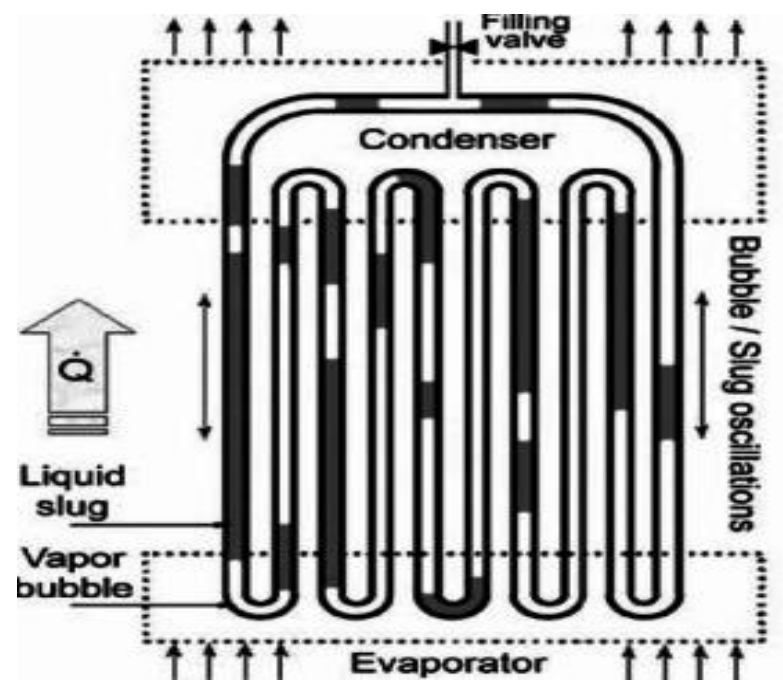

FIG.1.2..Pulsating heat pipe structure

It is predictable that the heat transfer performance of PHP may be different when charging with ethanol mixed with other working fluids. This paper studies the heat transfer performance of PHP with ethanol-based mixture working fluids compared to pure working fluids.

\section{EXPERIMENTAL APPARATUS AND DATA ANALYSIS}

\subsection{Experimental system}

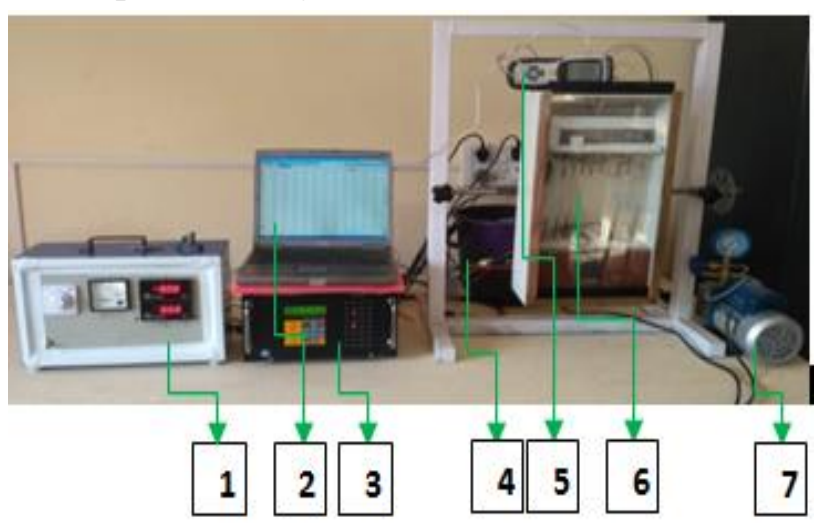

Fig. 2.1. Experimental Setup of PHP

1. Heat variac 2. Data Recording laptop
3. Datalogger 32 channel
4. water motor
5. Manometer
6. PHP
7. Vacuum pump

The No. of turns used in the CLPHP are 5, Material of tube is copper, Length of the evaporator section is $42 \mathrm{~mm}$, Length of condensation section is $50 \mathrm{~mm}$, Length of adiabatic section is $170 \mathrm{~mm}$, Inner diameter of tube is $2 \mathrm{~mm}$, outer diameter of tube is $3 \mathrm{~mm}$

The size of the channel has to be chosen not too large and not too small, as it will influence the working of the PHP. The specific performance of a PHP is reflected by the pulsating temperature of each measuring point, while the heat transfer performance of a PHP is reflected by the mean temperature of the evaporation section and overall thermal resistance. The number of measuring points in the evaporation section ranges from 13 to 22 and in the condensation section from 1 to 10 and $11 \& 12$ are tha thermocouples measuring inlet and outlet temperatures of the cooling water. Te (the mean temperature of the evaporation section) and Tc (the mean temperature of the condensation section) are determined after smooth running of the PHP.

The experimental parameters are Heat inputs given as 20 w, 40w , 60w , 80w, Fill ratio is 50\% and Working fluids are water, ethanol, acetone, water-ethanol, water- acetone, and the orientations are horizontal and vertical.

Table 1. Properties of the working fluid

\begin{tabular}{|l|l|}
\hline Working fluid & $\begin{array}{c}\text { Boiling point } \\
\left({ }^{\circ} \mathbf{C}\right)\end{array}$ \\
\hline Water & $\mathbf{1 0 0 . 0}$ \\
\hline Acetone & $\mathbf{5 6 . 2}$ \\
\hline Ethanol & $\mathbf{7 8 . 3 7}$ \\
\hline Water-Acetone & $\mathbf{7 8 . 1}$ \\
\hline Water-ethanol & $\mathbf{8 9 . 2}$ \\
\hline
\end{tabular}

\section{RESULTS AND DISCUSSIONS:}

The specific performance of a PHP is reflected by the pulsating temperature of each measuring point, while the heat transfer performance of a PHP is reflected by the mean temperature of the evaporation section and overall thermal resistance. The number of measuring points in the evaporation section ranges from 13 to 22 and in the condensation section from 1 to 10 and 11 and 12 are the temperature readings of cooling water inlet and outlet. Te (the mean temperature of the evaporation section) and Tc (the mean temperature of the condensation section) are determined after smooth running of the PHP:

$T_{c}=\frac{1}{10} \sum_{i=13}^{22} T_{c i}$

$T_{e}=\frac{1}{10} \sum_{i=1}^{10} T_{e i}$

The overall resistance of the PHP is determined by

$$
R=\frac{T_{g}-T_{F}}{Q}
$$

$\mathrm{Q}$ is the heat load supplied by the heating wire. Because the heat leak of the heat preservation block is small, the heat absorbed in the evaporation section is equal to Q.

\subsection{EXPERIMENTAL GRAPHS}

\subsubsection{Effect of pure fluids on thermal performance}

Initially, the thermal efficiency of PHPs using pure working fluids (water, ethanol, and acetone) is studied. The thermal resistance variation is observed by using below graphs. It is clear that the thermal resistance is Reduce with heat consumption decreases. The thermal resistance significantly falls to $40 \mathrm{~W}$, and consequently acts gradually in all PHP's. In general thermal activity relies on the thermo-physical properties of the operating fluids. The boiling point and latent vaporization heat are key parameters that affect liquid slug motion and vapor bubble in the tube. Dynamic viscosity and surface tension also play an important role during initialization in driving the liquid slug in a vertical position against gravity. 
Thermal resistance is greater at low heat intake, since flow is not introduced. The liquid bubbles oscillate because there were no appropriate pumping acts. In water PHP, as compared to other working fluids, the thermal resistance is more at low heat input due to high latent heat of vaporization. Therefore, for PHP to start circulation, more heat is required. During observation with heat inputs of up to $40 \mathrm{~W}$, flow was oscillating and then circulation began. Thus the thermal resistance decreases again, and the flow patterns change from wispyannular to annular flow. No dry-out state is found in PHP water as the boiling point is more than the heat supply.Different thermal-resistance levels in ethanol and methanol PHPs are identified. Due to low latent vaporization pressure, the circulations are started in ethanol and acetone PHP at lower heat, while the thermal activity of acetone PHP is erratic.

1. Variation of thermal resistance with the variation of heat input and in vertical position of PHP is shown in the below plot when fill ratio of water, acetone, ethanol is $50 \%$

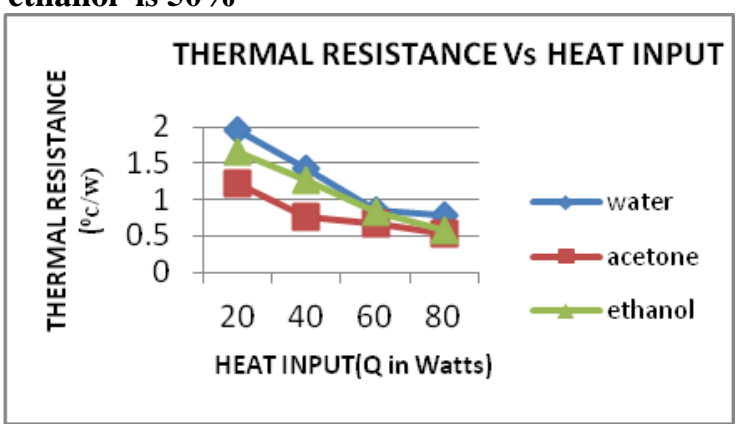

Fig.3.1.variation of thermal resistance of water, acetone, ethanol

Thermal resistance is gradually decreasing in the graphic representation by increasing the heat input,l minimum thermal resistance quality is achieved for acetone at $80 \mathrm{~W}$ heat input .

2. Variation of thermal resistance with the variation of heat input and in Horizontal position of PHP is shown in the below plot when fill ratio of water, acetone, ethanol is $50 \%$

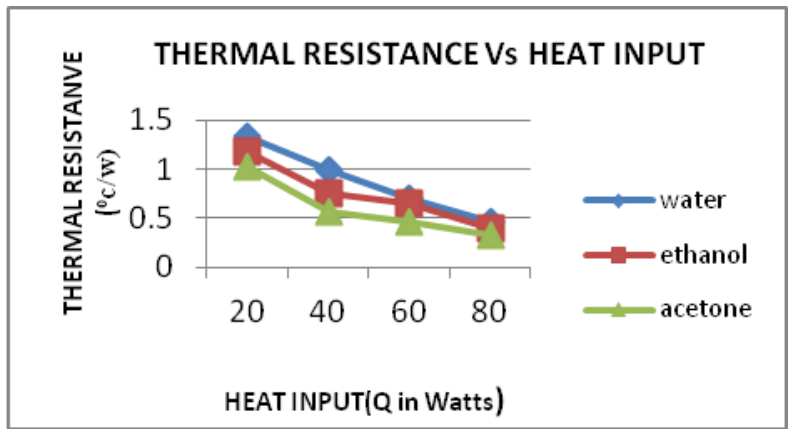

Fig.3.2.variation of thermal resistance of water, acetone, ethanol

Thermal resistance is gradually decreasing in the graphic representation by increasing the heat input. Minimum thermal resistance quality is achieved for acetone at $80 \mathrm{~W}$ heat input in $90^{\circ}$ orientation.

\subsubsection{Effect of binary fluids on thermal performance of} PHP at a mixing ratio of $1: 1$

The binary combination of water-ethanol, water-acetone (1:1 by volume) is used as the working fluid. This tests the chemical stability of those substances. Such binary mixtures are ideal solutions.. Thermophysical properties of binary fluids are therefore determined using the algebraic mean value equation. The thermal resistance of different binary fluids is plotted to test the thermal performance, as shown in the graph. It is obvious that thermal resistance activity in all binary fluids is almost similar. The thermal resistance reduces when contrasted with flat working fluid at initialization. Thus the thermal resistance variations depend on the thermophysical properties of binary fluids. The most significant properties for forecasting thermal performance are surface tension and latent vaporization pressure. The force of surface tension depends also on the shape and size of the liquid bubble and style of movement. Water-acetone PHP shows the highest thermal efficiency, Low residual heat and very high surface temperature. While water-ethanol PHPs thermal tolerance demonstrates mixed patterns as near thermophysical properties values. Thermal tolerance increases significantly from $20 \mathrm{~W}$ to $40 \mathrm{~W}$ heat intake, since no circulation is introduced. And gradually declines to $80 \mathrm{~W}$ heat input and then acts continuously, as long as observed bubbles. Thermal-performance activity over the broad operating range is highly consistent and stable.

1. Variation of thermal resistance with the variation of heat input and in vertical position of PHP is shown in the below plot when fill ratio of water-acetone, water-ethanol is $\mathbf{5 0 \%}$

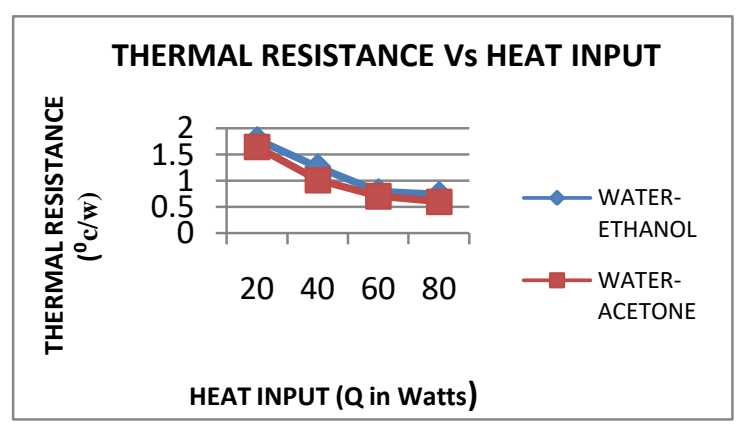

Fig.3.3.variation of thermal resistance of water-acetone, water-ethanol

Thermal resistance is gradually decreasing in the graphic representation by increasing the heat input. Minimum thermal resistance quality is achieved for water- acetone at $80 \mathrm{~W}$ heat input in $0^{\circ}$ orientation.

2. Variation of thermal resistance with the variation of heat input and in Horizontal position of PHP is shown in the below plot when fill ratio of water-acetone, water-ethanol is $\mathbf{5 0 \%}$

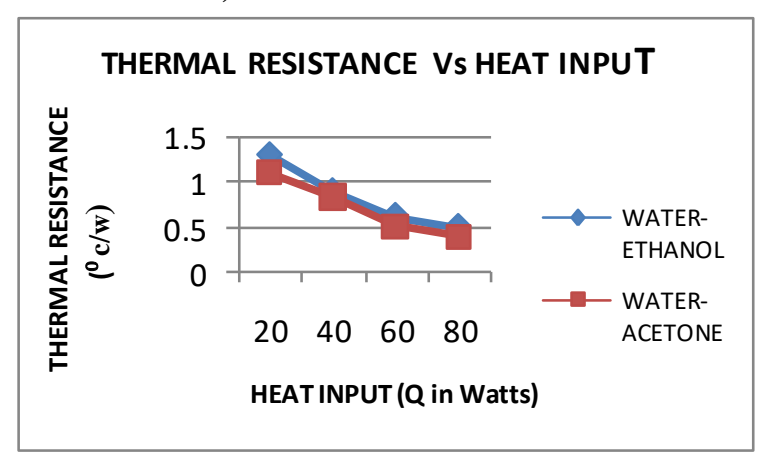

Fig.3.4.variation of thermal resistance of water-acetone, water-ethanol 
Thermal resistance is gradually decreasing in the graphic representation by increasing the heat input. Minimum thermal resistance quality is achieved for water- acetone at $80 \mathrm{~W}$ heat input in $90^{\circ}$ orientation.

\subsubsection{COMPARISION OF BINARY FLUIDS WITH THEIR PURE FLUIDS}

Water-acetone mixture in PHP is giving the better thermal performance than other binary fluid. Also clear that initiating from $20 \mathrm{~W}$ to $40 \mathrm{~W}$, the thermal resistance of all the working fluids is drastically diminishing . but from $40 \mathrm{~W}$ to $80 \mathrm{~W}$ heat input, all the working fluids giving less variation in their performance. In the comparision of water, ethanol, water-ethanol mixture, ethanol is giving better performance where as in the case of water, acetone, water-acetone mixture, pure acetone is giving less thermal resistance that means comparatively a better performance with other two fluids

1. Variation of thermal resistance given by water, ethanol with water-ethanol mixture in the vertical position.

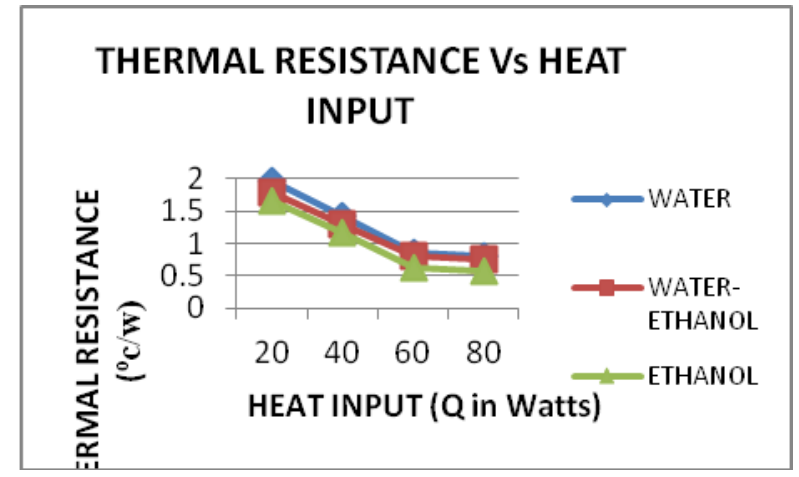

Fig.3.5.comparison between thermal resistance of water, ethanol, water-ethanol mixture

From the above comparision, we can conclude that in each case pure ethanol is giving lower thermal resistance compared to other fluids.

2. Variation of thermal resistance given by all the three working fluids in the Horizontal position.

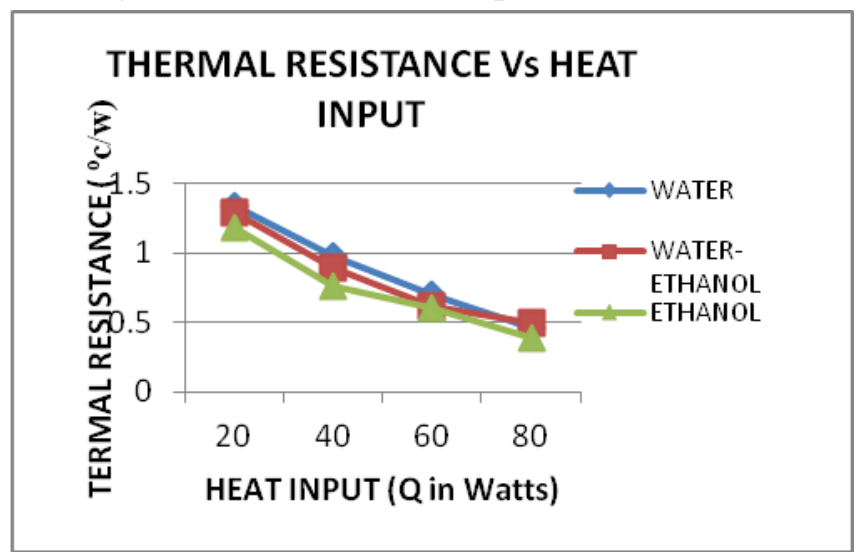

Fig.3.6.comparison between thermal resistance of water, ethanol, water-ethanol mixture

From the above comparision, we can conclude that in each case pure ethanol is giving lower thermal resistance compared to other fluids.
1. Variation of thermal resistance given by water, acetone with water-acetone in the vertical position.

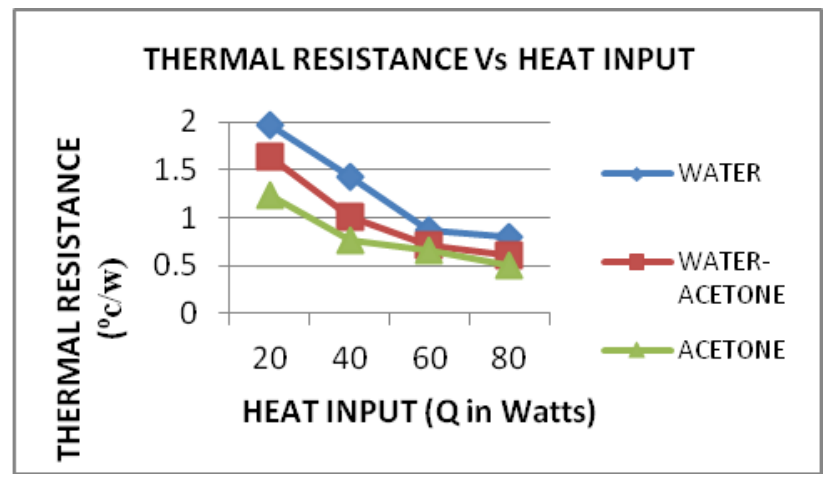

Fig.3.7.comparison between thermal resistance of water, acetone, and water-acetone mixture.

From the above comparision, we can conclude that in each case acetone is giving lower thermal resistance compared to other fluids.

2.Variation of thermal resistance given by water, acetone, water-acetone in the Horizontal position.

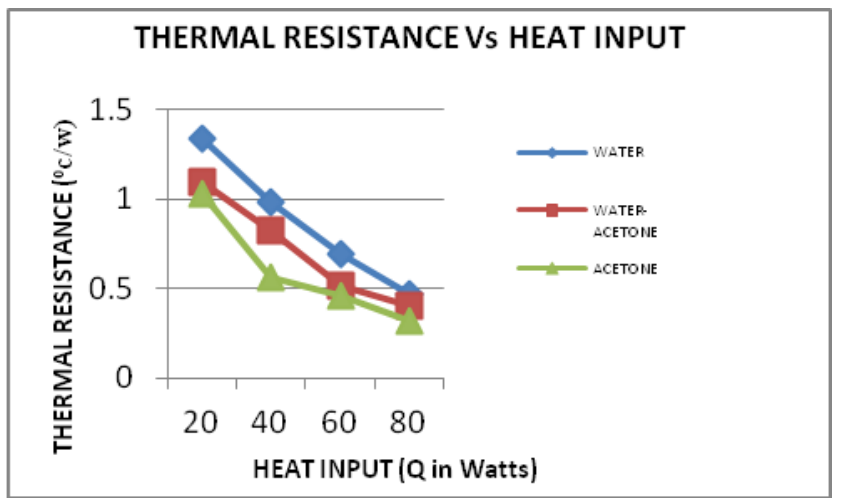

Fig.3.8.comparison between thermal resistance of water, acetone, water-acetone mixture.

From the above comparision, we can conclude that in each case acetone is giving lower thermal resistance compared to other fluids.

\subsubsection{THERMAL RESISTANCE OBSERVATION of ALL THE WORKING FLUIDS}

From the graphs, we can conclude that trends of thermal performance curves is same in profile, as the differences are less in physical neumeral values. Among all the working fluids in PHP, pure water has less thermal performance because of high thermal resistance, where as pure acetone has lesser thermal resistance. In all the cases we compared, among all the fluids, acetone gives the better performance in comparisons with the other pure and binary mixtures working fluids. 
1. Variation of thermal resistance given by all the working fluids in the vertical position

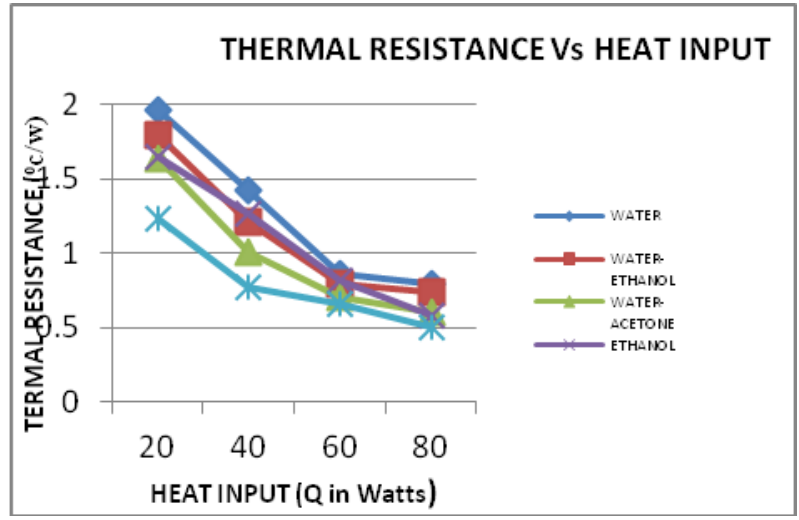

Fig.3.9.comparison between thermal resistance of water, acetone, ethanol, water-ethanol mixture, and water-acetone mixture.

From the above comparision, we can conclude that in each case acetone is giving lower thermal resistance compared to other fluids.

2.Comparing the variation of thermal resistance given by all the working fluids in the Horizontal position.

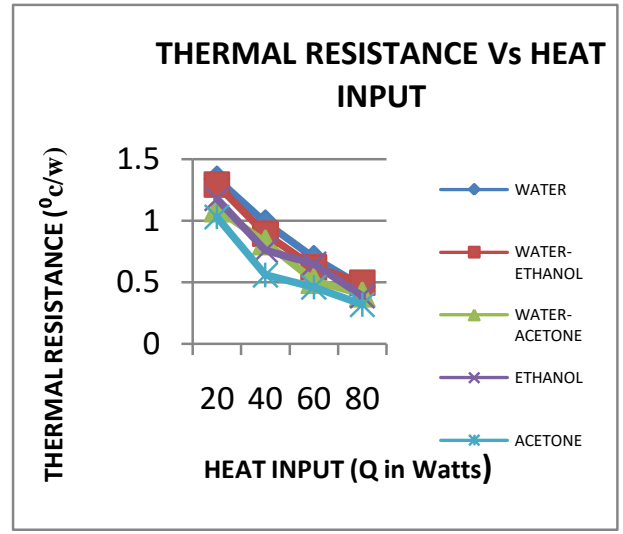

Fig.3.10.comparison between thermal resistance of water, acetone, ethanol, water-ethanol mixture, and water-acetone mixture.

From the above comparision, we can conclude that in each case acetone is giving lower thermal resistance compared to other fluids.

\section{CONCLUSIONS}

Empirical research was conducted to check the thermal resistance properties of PHP at various loading speeds and operational fluids. The results show that the heat transfer efficiency of PHP with a mixture is mainly correlated with physical properties, phase-change characteristics, and mass transfer resistance. An experimental analysis of the impact of pure and binary combination working fluid on thermal efficiency was performed on a closed loop pulsating heat pipes. Different working fluids have been shown. In different operating environments, specific fluids are helpful. Based on the applied $t$, an acceptable trade-off of specific thermophysical properties must be accomplished Thermo mechanical boundary environments. It is possible to draw the following key conclusions from the study:
1. For rising heat inputs, thermal tolerance is decreased for pure and discrete PHP working fluids. The dry-out for the PHPs of water-acetone and water-ethanol is at respectively $60 \mathrm{~W}$ and $80 \mathrm{~W}$ heat entry, approximating the algebraic mean values of the discrete mixture boiling point.

2. For the pure working fluids PHP, the sequence of the thermal resistances is acetone, ethanol and water from small to large. Whereas in binary mixture working fluid PHPs, the sequence of the thermal resistances is , water-acetone and water-ethanol from small to large.

3. In all the working fluids compared, it is observed that water is giving highest thermal resistance but pure acetone is offering lowest thermal resistance as resulting in better thermal performance.

\section{REFERENCES}

1. H. Akachi, Structure of a Heat Pipe, US 4921041, 1990.

2. H. Akachi, F. Polasek, P. Stulc, Pulsating heat pipes, in: 5th International Heat Pipe Symposium, Melbourne, Australia, 1996, pp. 208-217.

3. Mauro Mameli, Vincenzo Manno, Sauro Filippeschi, Marco Marengo, Thermal instability of a closed loop pulsating heat pipe: combined effect of orientation and filling ratio, Exp. Therm. Fluid Sci. 59 (2014) 222-229.

4. S. Rittidech, P. Terdtoon, P. Tantakom, et al., Effect of inclination angles, evaporator section lengths and working fluid properties on heat transfer characteristics of a closed-end oscillating heat pipe, in: 6th International Heat Pipe Symposium, ChiangMai, Thailand, 2000.

5. J Venkata Suresh, Dr.P.Bhramara, "CFD Analysis of Copper Closed Loop Pulsating Heat pipe" Materials Today: Proceedings 5 (2018) 5487-5495

6. Pramod R. Pachgare, Ashish M. Mahalle, “ Thermal performance of closed loop pulsating heat pipe using pure and binary working fluids". In Global Digital Central ISSN:2155-658X

7. R.R. Riehl, Performance Evaluation when using Nanofluids in Loop Heat Pipe and Pulsating Heat Pipe, SAE Technical Paper, 2007.

8. Yu-Hsing Lin, Shung-Wen Kang, Hui-Lun Chen, Effect of silver nano-fluid on pulsating heat pipe thermal performance, Appl. Therm. Eng. 28 (2008) 1312-1317.

9. Md. Riyad Tanshen, B. Munkhbayar, Md.J. Nine, Hanshik Chung, Hyomin Jeong, Effect of functionalized MWCNTs/water nanofluids on thermal resistance and pressure fluctuation characteristics in oscillating heat pipe, Int. Commun. Heat Mass Transfer 48 (2013) 93-98.

10. T. Katpradit, T. Wongratanaphisan, P. Terdtoon, P. Kamonpet, A. Polchai, Correlation to predict heat transfer characteristics of a closed end oscillating heat pipe at critical state, Appl. Therm. Eng. 25 (2005) 2138-2151.

11. Piyanun Charoensawan, Sameer Khandekar, Manfred Groll, et al. Closed loop pulsating heat pipes Part A: parametric experimental investigations, Appl. Therm. Eng. 23 (2003) 2009-2020.

12. Himel Barua, Mohammad Ali, Md. Nuruzzaman, Effect of filling ratio on heat transfer characteristics and performance of a closed loop pulsating heat pipe, Procedia Eng. 56 (2013) 88-95.

13. S. Wang, S. Nishio, Heat transport characteristics in closed loop oscillating heat pipes, in: 2005 ASME Summer Heat Transfe Conference July 17-22, 2005, San Francisco, California, USA, 2005.

14. X.M. Zhang, J.L. Xu, Z.Q. Zhou, Experimental study of a pulsating heat pipe using FC-72, ethanol, and water as working fluids, Exp. Heat Transfer 17 (2004) 47-67.

15. S. Rittidech, P. Terdtoon, P. Tantakom, et al., Effect of inclination angles, evaporator section lengths and working fluid properties on heat transfer characteristics of a closed-end oscillating heat pipe, in: 6th International Heat Pipe Symposium, ChiangMai, Thailand, 2000. 
Effect of Pure and Binary Fluids on Thermal Performance of Closed Loop Pulsating Heat Pipe

\section{AUTHORS PROFILE}

Mr. J. Venkata Suresh, Assistant Professor of Department of Mechanical Engineering, GRIET, completed her $\mathbf{M}$. Tech with Energy Systems Specialization from JNTU College of Engineering Hyderabad. B.Tech in Mechanical engineering from V R Siddhartha Engineering College, affiliated to ANU Guntur.

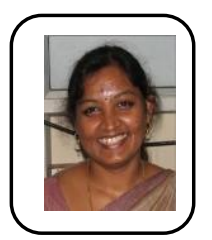

Dr P. Bhramara, Professor of Department of Mechanical Engineering, JNTUCEH completed her PhD from JNTU Hyderabad. She holds Master Degree in Refrigeration and Air Conditioning. She was graduated B.Tech from JNTU College of Engineering.

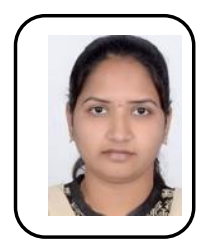

K. Nagasri, completed her B.Tech Mechanical Engineering from JNTUHCEJ, Karimnagar, and Currently she is pursuing her M.Tech Thermal Engineering from Gokaraju Rangaraju Institute of Engineering and Technology, Hyderabad. 